\title{
IT AS A PLATFORM FOR COMPETITIVE AGILITY
}

\author{
V. Sambamurthy \\ Michigan State University, USA
}

\begin{abstract}
Agility is a fundamental capability for firms to compete in contemporary business environments and underlies the continual launch of innovative competitive moves through speed, surprise, and disruption. Winners in today's economy succeed because of agility in innovative products, markets, channels, and customer segments. Advances in information technologies and the emergence of information management as a superior locus of customer loyalty and value creation have spurred interest in leveraging IT as a platform for competitive agility. Investments in information technology could provide firms with strategic digital options that they can apply to sense opportunities for competitive action and respond with speed and innovation. Therefore, there is a growing interest in understanding how information technologies can be managed as a platform for competitive agility.
\end{abstract}

Key words: Agility, Organizational Capabilities, Digital Options

This panel develops insights about the linkages between IT and agility through a focus on the following questions:

1. What is competitive agility?

2. How could IT provide a platform for competitive agility?

3. What organizational and IT management practices are likely to position firms to exploit their IT infrastructures and be agile?

The format of the panel will be as follows:

Panel Chair and Moderator: Ritu Agarwal, Tyser Professor of Information Systems, University of Maryland, College Park, ragarwal@ rhsmith.umd.edu

\section{Panelists:}

1. Jeff Sampler, Professor of Information Systems, London Business School and EESE Business School, Barcelona, Spain, jsampler@london.edu 
2. V. Sambamurthy, Eli Broad Professor of Information Technology, Michigan State University, East Lansing, smurthy @ msu.edu

3. Robert W. Zmud, Michael Price Chair in MIS, University of Oklahoma, Norman, rzmud@ou.edu

Jeff Sampler will argue that there is need to redefine the role that technology and people must play in organizations. He will explore new models of strategic thinking, technology management, and the vital traits for senior business and technical management in this turbulent world. He will emphasize two roles of technology in the agile organization - being a major driver of organizational turbulence, as well as a potential solution. A simple focus on technology to create agile organizations is a very narrow solution and there is a need to explore the integrative role of strategy, management, and organizational structures.

V. Sambamurthy will focus on two specific concepts: competitive agility and strategic digital options. He will draw upon recent research to describe how these two concepts are vital to rethinking the role of IT as a digital options generator.

Robert Zmud will first describe the different roles that IT can play as a platform for agility. Next, he will focus attention on some organizational capabilities, structures, and processes that are necessary to unleash the digital platforms and engage in agile competitive moves. Implications of this perspective for research and practice will be discussed.

Each panelist will weave together insights from their current research, consulting, and interactions with executives to provide meaningful insights both for research and managerial action. 